\title{
Who Needs the Sociology of Health and IIIness? A New Agenda for Responsive and Interdisciplinary Sociology of Health and Medicine
}

\author{
Sakari Karvonen ${ }^{1 *}$, Laura M. Kestilä ${ }^{1}$ and Tomi E. Mäki-Opas ${ }^{2}$ \\ ${ }^{1}$ Department of Health and Social Care Systems, National Institute for Health and Welfare, Helsinki, Finland, ${ }^{2}$ Department of \\ Social Sciences, University of Eastern Finland, Kuopio, Finland
}

OPEN ACCESS

Edited by:

Nicola Kay Gale, University of Birmingham, United Kingdom

Reviewed by: Joana Almeida

Royal Holloway, University of London, United Kingdom Maria Berghs, De Montfort University, United Kingdom

*Correspondence: Sakari Karvonen

Sakari.Karvonen@thl.fi

Specialty section:

This article was submitted to

Medical Sociology,

a section of the journal

Frontiers in Sociology

Received: 04 September 2017 Accepted: 20 March 2018 Published: 05 April 2018

Citation:

Karvonen S, Kestilä LM and Mäki-Opas TE (2018) Who Needs the Sociology of Health and IIIness? A New Agenda for Responsive and

Interdisciplinary Sociology of Health and Medicine. Front. Sociol. 3:4

doi: 10.3389/fsoc.2018.00004
Health and medicine are key areas of sociological specialization, but in the face of rapid global challenges, they are changing. The need for change is becoming more and more urgent and the relevance of some of the traditional approaches, frameworks and theoretical perspectives should be evaluated. The aim of this article is to reflect on this issue and to explore what could be done in response to scientific and societal developments. We argue that more innovative approaches and better research questions would guide us to be more responsive as medical sociologists. In particular, we think that interdisciplinary and translative work hold untapped potentials for our field.

Keywords: health inequalities, social determinants of health, intersectionality, life style, health technology

For quite some time, the sociology of health and medicine has been an important specialty of sociology. Over the past decades, there has been an active dialogue, not only within general sociology, but also within other scientific fields, most notably medicine and, more recently, social policy research and economics. This has enriched the methodological and theoretical approaches available for the sociology of health and medicine. Even though research questions have varied in topic largely from one period and paradigm to another, the number of research themes has persisted, and has found new nuances. The manifold questions, e.g., related to the social, health, and economic conditions of the aging population, continue to be accurate. In addition, even though health has continuously improved, health inequalities and their novel manifestations, continue to be visible. Climate change and global migration, in addition to the effects of digitalization and new technologies on work, work-life balance, health and services, are among the newer developments that are strongly influencing the interests and discourses within the field of sociology of health and medicine ${ }^{1}$.

In this article, we briefly address some key themes of the sociology of health and medicine, and highlight new approaches and novel research themes. We also outline the future potential of the sociology of health and medicine. Our main argument is that, unless we become more responsive to recent challenges and more engaged with other scientific approaches and frameworks, we may run the risk of losing the momentum: that of increased interest in health among the general population along with greater opportunities to explore health, illness, and medicine. In addition to old themes gaining novel nuances, global phenomena are bringing about unforeseen problems resulting from interdependences between different fields. These grand questions are increasingly demanding also our attention. Even though some of the issues are already dealt with current sociology of health, they

\footnotetext{
${ }^{1}$ We have adopted the concept of sociology of health and medicine to highlight both the scholarly and the institutional linkages of the field with medicine. "Health" is here denoted to also cover the other commonly applied terms such as health and illness, healing, as well as medical sociology. For simplicity, we also apply health sociology to refer to these fields.
} 
may require new alliancies, audiences, and responses. We are not claiming that all this would be completely novel, but that more can be gained from a more intense exchange between our specialty and the "grand" sociological theories, from more imaginative interaction with new "publics" of sociology (Burawoy, 2005) and from translative work crossing scientific boundaries. This notion points to more general approaches as opposed to the tendencies leading to increasing differentiation and specialization. Here the new agenda for sociology of health proposes going against the grain of scientific development.

Supporting our claim, a similar debate about the new sociological directions has recently been raised by Bradby (2016). She states that the challenge for this field is to continue its critical approach to social processes of health and illness and to integrate scientific evidence with people's experiences. Global challenges of sociology have also been debated recently by Bhambra and de Sousa Santos (2017), who suggest that new forms of inequality and injustice will rise-a problem that will need to be dealt with in the field of sociology.

\section{DEMOGRAPHIC CHANGES AND THEIR IMPLICATIONS WILL REMAIN IMPORTANT GLOBAL TOPICS}

One of the traditional key themes in the sociology of health and medicine has been demographic changes.

The effects of the population aging are visible in the functional capability and quality of life of the population. People live longer, and a large part of the additional years are healthy (WHO, 2016), even though the elderly tend to live at home longer and with worse health. As the population dependency ratio is weakening and the share of the elderly population will grow considerably in the future, challenges regarding care and services are gaining importance. It has been claimed that aging is becoming more normative as lives become longer; the elderly are expected to participate socially and to lead a healthy life. This represents a significant change: old age was previously seen as a phase of life characterized by passivity and frailty (Higgs and Gilleard, 2015). The sociological study of aging shows, however, that with medicalization there is also a risk of perceiving aging and old age only in terms of problems and threats. This creates the risk of old age not being seen as a desirable and multifaceted phase of life.

Another quite obvious global challenge derives from immigration trends. The greatly increased numbers of refugees that have been a combined result of climate change and financial or political crises in the areas of origin have dramatically changed many so-called Western countries. Immigrants may provide new opportunities for receiving societies by supplementing the employment sector in otherwise aging populations, but they may also bring new challenges, e.g., for the social and health care sectors. Sociological sensitivity provides perspectives for understanding the cultural backgrounds, norms and behavioral traits, as well as their interlinks with social determinants among the immigrants and asylum seekers thus highlighting the importance of social structures in leading to ethnic health inequalities. Moreover, sociological perspectives may provide the understanding necessary to facilitate the acculturation and settlement of the asylum seekers into the receiving societies. Due to selective migration, health inequalities among immigrants may even be reversed in comparison with the native population. Personnel in the social and health care sector should have sufficient knowledge of the immigrants' cultural and other backgrounds to be able to succeed in promoting their health and welfare.

\section{HEALTH INEQUALITIES AND THE LEGACY OF AUSTERITY}

Health inequalities continue to be one of the key themes in this field. Inequalities in health remain persistent in many countries and globally, health and illness are distributed in an increasingly unequal way. WHO (2008) pointed out that illness is becoming increasingly intertwined with poverty and deprivation. Even though research on health inequalities is already an established subject area with a long tradition, serious political attempts to tackle health inequalities have been rare. Although many policy programmes and international resolutions have been put in place, their execution has often suffered from conflicting interests, too few resources and a limited scope that has not allowed addressing the root causes or key drivers of health inequalities. Furthermore, health inequalities raise compelling ethical questions. Current societies are increasingly characterized by inequalities in wellbeing in a broad sense, which stresses the importance of decreasing socioeconomic differences in health in future health and welfare policies. A recent European comparative study suggests that the persistent health inequalities may be, in fact, a by-product of the modern welfare state (Mackenbach, 2016). If this is the case, decreasing these inequalities would require many extreme actions.

Further, tackling inequalities is more and more challenging due to the rapid changes facing current societies. Worldwide, many countries have faced large-scale social challenges due to the international financial crisis: high levels of unemployment and social exclusion. The era of austerity has been directly observable in many countries, also in the social, political, and cultural determinants of population health (Stuckler and Basu, 2013). There is a growing understanding of the fact that economic cycles, structures and societal conditions necessarily reflect wellbeing and related inequalities over a long period of time. More comparative studies are needed to identify successful reactions to limiting the health consequences of economic strains. Analyses on viable solutions in different welfare models are necessary, a question that calls for more context-sensitive research.

Even though the global economy has recently shown signs of more positive trends, the legacy from the age of austerity is likely to have left far-reaching effects. These effects may result in a growing generational gap if future generations suffer more from adversities in health as well as a general lack of future prospects. Thus, intergenerational disadvantages of health continue to be among the key themes of the sociology of health, but enriched with new research imperatives as part of the new 
agenda. Comparisons between different birth cohorts and time periods evoke questions of critical moments and turning points as determinants of health and illness. Along with the themes concerning the aging population, new research questions arise from the later periods and transitions of life, while current research emphasizes early childhood conditions and experiences. Forthcoming research interests also include identifying associations and causal effects that have influence over several generations.

\section{HEALTHY LIFE-STYLE RESEARCH FACES NEW CHALLENGES}

The complexity of healthy lifestyles is another traditionally important theme. Growing individual tendencies may lead to temporary phenomena (such as fashionable diets and health gadgets) that may benefit small parts of the population, and thus widen health inequalities further. Identifying the importance of these occurrences and their consequences is an intriguing task for the field of sociology of health and medicine. On this basis, it appears that new opportunities to reduce health inequalities emerge along with trends focusing on an individual's own agency, which have sometimes been referred to as the "third way" of health promotion (Abel and Frohlich, 2012). Some researchers, such as Schrecker and Bambra (2015), emphasize the macro-level by illustrating the consequences of neo-liberalism. This dictates the necessity of better understanding the multi-layered nature of health inequalities in the future. Partly this complexity is likely to result from the increasingly circulatory nature of sociological research (Mesny, 2009) as it is becoming used and abused by conventional and social media. The critical sociology of health has also recently demonstrated the intersections of health by showing the complex and historically patterned interaction between social position (e.g. by class, ethnicity, and gender), identity and exercise of power (Kapilashrami et al., 2015). Due to these socioeconomic interdependencies a more comprehensive response is required that combines the intellectual efforts of sociologists with many other sciences.

Identifying factors that determine lifestyles is also a theme that is likely to remain high on the research agenda. Social and health services and policies are facing new challenges, for example, due to an ever-increasing mobile and multi-ethnic population. Health sociology that embraces cultural multiplicity and heterogeneity has much to contribute under these societal conditions. Similarly Bradby et al. (2017) suggest that the concept of superdiversity is useful when studying social production of health and illness in a multi-cultural context.

From a sociological perspective, a health-promoting lifestyle is to be understood in a broader sense than simply as behavior related to health. Related research shows that choices, e.g., related to eating or physical activity, that an individual or a social group makes may modify many other factors that are not directly associated with health. These include factors such as pleasure or sociability, which are based on values, norms, and potentials. The origins of the sociology of health are multimethodological, which corroborates with the multi-etiological nature of determinants of health. New kinds of research material (such as digital material) and other open data allowing novel studies are becoming available, which promises better and a more nuanced understanding of the core questions of the research area.

Further, from a critical perspective, the very praxis of health promotion has called for sociological scrutiny. Again, while the promise of technology may be great, the social and identity consequences of the related practices are still poorly understood.

\section{DEVELOPING HEALTH TECHNOLOGY OPENS UP NEW ETHICAL PERSPECTIVES}

Classic concepts, including norms, values, and attitudes related to health, should remain subjects for health sociologists to explore. When (late) modern, post-industrial societies aim to become more effective and to intensify social and health care systems, cost-efficiency often appears to be the key ideology guiding operative planning. Aspiring financial benefits may have led to surprising side-effects, in that health care is becoming a commodity. From this point of view, how health is valued is extremely important. The societal, juridical, ethical, and moral questions on health care, pharmaceutic and lifemaintaining industry will most likely receive more emphasis in the sociology of health. Abortion, genetic engineering, and euthanasia are some examples of the more traditional themes, but many new phenomena, such as gene banks and nanotechnology, bring about questions that are likely to raise concern.

Along with the development of health technology, new ethical, social but also economic dimensions on human body have opened up. These changes signify that the human body is becoming perceived as a biobank or raw material consisting of genes, cells and tissues. Its utilization becomes more and more interesting, and it is the object of an increasing number of technological innovations. Societies will have to outline guidelines to govern the economic activity that concentrates on the biology of bodies. Appealing to individuals' autonomy to control their own bodies will be insufficient given that not everyone is equally prepared to maintain autonomy, take children as an example (see Lafontaine, 2016). As they reach new areas, screenings involve ethical, juridical and social risks and uncertainties. As they become routine, increases the risk of underestimating the anxiety and the helplessness experienced by lay people. Furthermore, screening is not only a medical but also a social intervention (Armstrong and Eborall, 2012).

Along with the development of technology, digital applications are evolving, as well as spatial information, which offers novel methodological options for the sociology of health and medicine. Whether the focus is on the choices people make, the prevention of health complaints, or the social structures framing them, big data will open up completely new research settings and questions (Lupton, 2015). Similar opportunities lie in self-produced and self-curated data. 
We have already witnessed how these new technologies affect our social and health practices fundamentally. The sphere of their ramifications is yet unforeseen but the existing approaches to exploring new technologies need to be developed already simply due to their omnipresence.

\section{THE FUTURE: WHO NEEDS THE SOCIOLOGY OF HEALTH AND MEDICINE?}

The knowledge and critical perspectives of health and medical sociology are especially useful for people working in the health care sector and policy makers in the field, as they highlight the associations and causal relations of health and illness and of societal, social, and behavioral factors. Health and illness can be understood better by scrutinizing a person as an individual, as part of a social group, and part of society in general. Whether international, national, regional or local decision making or planning on health policy, the sociology of health is useful. Recent examples of emergent themes include health of vulnerable groups, and cross-border health care. These subjects can be approached by identifying the social background, inequalities, and the effects of social changes and structures that lie behind access to and quality of care.

Additionally, it is crucial to understand the values and norms that guide reforms. The planning of health system reforms requires the knowledge of health sociology in order to be able to grasp knowledge of the unofficial and unstructured socio-cultural practices that either allow or hinder cross-sectional integration. Further, from this perspective the unofficial work community, the various power structures and interaction patterns can be highlighted.

Understanding not only societal structures and changes but also the associations between various social and behavioral factors and people's health have become more and more important. Knowledge of the sociology of health can be strengthened, e.g., by incorporating it into teaching in other fields such as in universities and vocational institutes. In many countries, the sociology of health remains a focal part of teaching in medical faculties, which is important in avoiding the individualistic ethos of the traditional biomedical perspective. The tendency of biomedicine to focus on phenomena located "under the skin" needs to be supplemented with knowledge of what goes on "outside the skin." Translational medicine, which conventionally refers to transdisciplinary research within medicine, would benefit from collaboration involving the field of sociology of health, e.g., when posing research questions and framing scientifically relevant approaches. Communicating these questions to students in certain fields is difficult, as some, especially medical students, may adhere to a certain

\section{REFERENCES}

Abel, T., and Frohlich, K. L. (2012). Capitals and capabilities. Linking structure and agency to reduce health inequalities. Soc. Sci. Med. 74, 236-244. doi: 10.1016/j.socscimed.2011.10.028 understanding of the character of medical practices. Both traditional sociological approaches to health remain vital; whether it is called the sociology "of" medicine or sociology "in" medicine, ideally these perspectives constitute a joint agenda to address the same questions from different angles.

Therefore, the potential of health sociology is not limited to the fields where it stands "naturally"-social sciences and medicine-but also applies other areas. These less obvious fields include city and community planning and environmental studies. Sustainable development, ecology, and community planning gain from understanding the everyday choices and factors that determine healthy lifestyles. More often than not, promoting health and sustaining the environment require complementary rather than conflicting measures.

There is large potential for theoretical perspectives that also provide applicative possibilities. This potential can be realized by examining the themes of individual and societal responsibility, the role of other spheres of policy in reaching the goals of health policy, or the factors that influence availability, accessibility, and acceptability of services.

To conclude, we are not arguing for a completely new paradigm. Rather, we see that the sociology of health and illness of today has the potential to serve many more "clients" than before. This is due to the increasing need of knowledge on complex health-related phenomena. However, this epistemological need can only be fulfilled provided that sociologists working in the area remain sensitive to emergent themes, and that interlinks with other fields are maintained. This requires new forms of data production and more intense interaction with end users and stakeholders than what Academia has traditionally been accustomed to. This means stepping out of the traditional superiority position as it is described by Mesny (2009) into a position that is accountable and dialogical with the "publics," whether lay people or other professionals. To paraphrase one of the key concepts of the sociology of health: without the Sense of Health Sociology we remain incomplete in trying to grasp the essence of human nature. In other words, the sense of health sociology dictates a renewed role for the field-one that is more active and responsive, more transdisciplinary, unorthodox, and curious.

\section{AUTHOR CONTRIBUTIONS}

SK has drafted the manuscript. All authors have contributed to conceptualizing, outlining, and developing the manuscript further.

\section{FUNDING}

The work was funded by our respective institutions.
Armstrong, N., and Eborall, H. (2012). The sociology of medical screening. Past, present and future. Sociol. Health Illn. 34, 161-176. doi: 10.1111/j.1467-9566.2011.01441.x

Bhambra, G. K., and de Sousa Santos, B. (2017). Introduction: Global challenges for sociology. Sociology 51, 3-10. doi: 10.1177/0038038516674665 
Bradby, H. (2016). Research agenda in medical sociology. Front. Sociol. 1:14. doi: $10.3389 /$ fsoc.2016.00014

Bradby, H., Green, G., Davison, C., and Krause, K. (2017). Is superdiversity a useful concept in European medical sociology? Front. Sociol. 1:17. doi: $10.3389 /$ fsoc. 2016.00017

Burawoy, M. (2005). The return of the repressed: recovering the public face of U.S. sociology, one hundred years on. Ann. Am. Acad. Polit. Soc. Sci. 600, 68-85. doi: $10.1177 / 0002716205277028$

Higgs, P., and Gilleard, C. (2015). Rethinking Old Age. Theorising the Fourth Age. London: Palgrave Macmillan.

Kapilashrami, A., Hill, S., and Meer, N. (2015). What can health inequalities researchers learn from an intersectionality perspective? Understanding social dynamics with an inter-categorical approach. Soc. Theor. Health 13, 288-307. doi: $10.1057 /$ sth.2015.16

Lafontaine, C. (2016). "My body, my capital. Biocitizenship in the era of Neoliberalism," in Plenary at the $16^{\text {th }}$ European Society for Health and Medical Sociology Conference. (Geneva).

Lupton, D. (2015). Digital Sociology. London; New York, NY: Routledge.

Mackenbach, J. (2016). "The persistence of health inequalities in modern welfare states. The explanation of paradox," in Health Inequalities in Europe. New Insights from Comparative Studies, ed J. P.Mackenbach (Rotterdam: Erasmus MC), 179-192.

Mesny, A. (2009). What do 'we' know that 'they' don't? Sociologists' versus nonsociologists' knowledge. Can. J. Sociol. 34, 671-695. Available online at: https://journals.library.ualberta.ca/cjs/index.php/cjs/article/view/6313
Schrecker, T., and Bambra, C. (2015). How Politics Makes Us Sick. Neoliberal Epidemics. London: Palgrave Macmillan.

Stuckler, D., and Basu, S. (2013). The Body Economic. Why Austerity Kills. Recessions, Budget Battles, and the Politics of Life and Death. New York, NY: Basic Books.

WHO (2008). Closing the Gap in a Generation. Health Equity through Action on the Social Determinants of Health. Final report of the commission on social determinants of health. Geneva: World Health Organization. Available online at: whqlibdoc.who.int/publications/2008/9789241563703_eng. pdf (Accessed December 16, 2016).

WHO (2016). Global Health Observatory Data. Healthy Life-Expectancy at Birth Available online at: who.int/gho/mortality_burden_disease/life_tables/hale/en/ (Accessed December 26, 2016).

Conflict of Interest Statement: The authors declare that the research was conducted in the absence of any commercial or financial relationships that could be construed as a potential conflict of interest.

Copyright (c) 2018 Karvonen, Kestilä and Mäki-Opas. This is an open-access article distributed under the terms of the Creative Commons Attribution License (CC $B Y)$. The use, distribution or reproduction in other forums is permitted, provided the original author(s) and the copyright owner are credited and that the original publication in this journal is cited, in accordance with accepted academic practice. No use, distribution or reproduction is permitted which does not comply with these terms. 